\title{
PLATH, Sylvia. A redoma de vidro. Tradução de Chico Mattoso. São Paulo: Globo, 2014. 280 p.
}

\author{
Bárbara Costa Ribeiro* \\ Universidade Federal do Ceará
}

Com o intuito de identificar determinadas marcas e escolhas tradutórias de acordo com épocas de publicação, comparamos aqui a versão brasileira mais recente do romance de Sylvia Plath, traduzido por Chico Mattoso e lançado em 2014 pela Biblioteca Azul (selo da Globo Livros), com outra edição do romance, de 1999, pela editora Record e traduzido por Beatriz Horta. Ambas as edições brasileiras são cotejadas ainda com o texto original em inglês, The bell jar (1963), em republicação de 2005 pela HarperCollins, com o selo Harper Perennial, coleção Modern Classics.

The bell jar, intitulado $A$ redoma de vidro, no Brasil, é o único romance da poeta americana, que o lançou primeiramente na Inglaterra, sob pseudônimo, em 1963, o ano de seu suicídio. Após o dramático episódio, o mercado editorial americano redescobriu o romance de Sylvia, junto a uma considerável camada da crítica que se ocupou de dissertar sobre aspectos ditos "confessionais" da obra, considerando essas esferas como instâncias de disseminação

\footnotetext{
* Mestranda em Literatura Comparada no Programa de Pós-Graduação em Letras da Universidade Federal do Ceará. Fortaleza, Ceará, Brasil. E-mail: costaribeirobarbara@gmail.com
} 
de uma leitura autobiográfica, lidando com o romance como uma espécie de manual para se entender a vida íntima de Sylvia Plath.

O nome da poeta foi rapidamente absorvido pela cultura pop e transformado em ícone, colocando-a no rol das "escritoras suicidas". O fascínio ao redor da imagem atormentada de Sylvia alimentou inúmeras republicações e estudos de seu romance, estabelecendo uma tradição de leitura que identifica esta obra em prosa com uma espécie de diário para também decifrar as imagens de sua poesia, e adentrar ainda sua rotina enquanto mulher, mãe, esposa e dona-de-casa.

A história de $A$ redoma de vidro registra muitas intersecções com a vida de sua autora, mas, mesmo se o encaixarmos na categoria das biografias, o livro ainda é um romance, construção narrativa ficcional, despendendo todo um elenco de personagens fictícias e lançando mão de diversos mecanismos poéticos na construção das cenas, que interessam muito mais ao universo da trama do que à investigação da autoria.

No que diz respeito à temática, o romance traz à luz a figura do feminino, o desejo de ser escritor, dualismos entre a vida doméstica e a carreira, os ideais da juventude, as complicadas e caprichosas relações familiares, os tabus do sexo, perpassando ainda assuntos como loucura, depressão, a ideia obsessiva da morte e a própria questão do suicídio.

O que nos interessa nesta resenha é mostrar de que forma essa tradição de transmissão e recepção da obra pode ter influenciado o trabalho tradutório mais recente, especificamente no que diz respeito à edição mais nova, de 2014, aqui analisada. Ademais, examinamos ainda passagens do romance de valor plástico e apuro técnico, que apontam para uma leitura poética.

Na trama, encontramos a personagem Esther Greenwood, universitária, filha de família cristã de Boston, não muito rica, que se 
encontra em Nova York durante as férias de verão, com uma bolsa para escrever e participar do corpo editorial de uma revista feminina; tudo envolto numa aura de glamour e de aventura. Esther e outras garotas se encontram hospedadas num hotel em Nova York, já há algum tempo, quando toma curso a narrativa, e ali vivem pequenos conflitos no ambiente de sociabilidade entre garotas, que logo se tornam dramas maiores.

Esther Greenwood, protagonista e narradora da trama, seguirá uma trajetória que mescla a confusão de seus anseios com as expectativas projetadas sobre ela, a crescente aversão à ideia de se casar com Buddy Willard, rapaz com que se encontra há algum tempo e que agrada à mãe viúva. A personagem permite, através de seu profuso exercício mental, que a história vá ganhando maior espaço, até que se aprofundem os dramas e se agudizem as questões aparentemente superficiais que vão se pontuando desde a primeira página.

Vamos entendendo o mundo pessoal e íntimo de Esther conforme esses conflitos se adensam, conflitos como o ser mulher na cidade e estar só, ou ver-se a todo instante questionando a lógica do mundo e o funcionamento da própria cabeça, e o desejo ainda de ser ela mesma uma escritora. Assim, Esther é conduzida às primeiras tentativas de suicídio, até que, de chofre, essa moça deprimida é instalada numa clínica para jovens loucas; o leitor percebe, então, que fora preparado brandamente para chegar àquele ponto da narrativa.

Conhecendo o enredo e cotejando as duas traduções, nos deparamos com passagens inaugurais do romance, que evidenciam importantes escolhas tradutórias. A edição de 1999 diz:

Era um verão estranho e opressivo aquele em que eletrocutaram os Rosenberg, e eu não sabia o que estava fazendo em Nova York. Não entendo de pena de morte. A ideia de ser eletrocutada me dá náuseas e esse era o único assunto dos jornais - manchetes garrafais me olhavam em cada esquina 
e em cada sufocante saída de metrô cheirando a amendoim. Aquilo não tinha nada a ver comigo, mas eu não conseguia parar de pensar em como seria ser queimada viva, até os nervos. (PLATH, 1999, p. 7).

Na edição mais recente, temos este mesmo primeiro parágrafo do capítulo 1 do livro traduzido da seguinte forma:

Era um verão estranho, sufocante, o verão em que eletrocutaram os Rosenberg, e eu não sabia o que estava fazendo em Nova York. Tenho um problema com execuções. A ideia de ser eletrocutada me deixa doente, e os jornais falavam no assunto sem parar - manchetes feito olhos arregalados me espiando em cada esquina, na entrada de cada estação de metrô, com seu bafo bolorento de amendoim. Eu não tinha nada a ver com aquilo, mas não conseguia parar de pensar em como seria acabar queimada viva até os nervos. (PLATH, 2014, p. 7).

O que se percebe nesse momento inicial, entre uma tradução e outra, é que a de 1999 opta por maior liberdade, moldando com mais autonomia seu texto, enquanto a versão recente (de Mattoso) parece se aproximar bem mais da dicção do texto original, uma vez que mantém o "bolorento" da construção em inglês "fusty" - que pode também ser traduzido como "sufocante", mas cuja ocorrência como algo relativo a bolor parece mais pertinente, querendo tornar o ar quase palpável, mais de acordo com a imagem do original, quando este descreve "the fusty, peanut-smelling mouth of every subway” (PLATH, 2005, p. 1).

De forma semelhante, Mattoso opta por iniciar o parágrafo anunciando que "era um verão estranho, sufocante", assim bem próximo da construção original em inglês, que, como é frequente no idioma, se dá, na organização da frase, com a proximidade espacial dos dois adjetivos que descrevem aquele verão: "It was 
a queer, sultry summer, the summer they eletrocuted the Rosenbergs" (2005, p. 1).

Na edição de 2014, a ideia de ser eletrocutada "deixa doente" a personagem, e as manchetes se mostram "feito olhos arregalados" - ambas construções frasais também algo mais próximas do original, com o literal sentimento de to make someone sick, e da sentença "goggle-eyed headlines". No original: "The idea of being eletrocuted makes me sick, and that's all there was to read about in the papers-goggle-eyed headlines staring up at me on every street corner [...]" (2005, p. 1).

Essas escolhas da edição mais recente, por manterem o tom das estruturas do inglês, dentro das construções em português, parecem querer guardar no português brasileiro a cinética do texto original, como um lembrete da identidade do texto traduzido.

Em outra passagem, a tradução de Horta (1999), por sua vez, traz o seguinte:

Continuei ouvindo falar nos Rosenberg no rádio e na redação, até não conseguir mais tirá-los da cabeça. Foi como a primeira vez em que vi um cadáver. Nas semanas seguintes, a cabeça do cadáver - ou o que sobrou dela - pairava por trás dos ovos com bacon do meu café da manhã e da cara de Buddy Willard, o responsável por eu ver o cadáver, e daí a pouco parecia que eu estava puxando a cabeça do defunto por um barbante, como um balão sem nariz fedendo a formol (PLATH, 1999, p. 8).

Na tradução de Mattoso, o mesmo trecho aparece com um menor rigor na descrição dos objetos, elegendo imagens mais simples, ingênuas até, de acordo com o que observamos nas palavras "barbante" e "formol", "cordinha" e "vinagre", mantendo-se a tradução mais próxima ao tom original: 
[...] Passei as semanas seguintes com a cabeça do cadáver - ou o que tinha restado dela - flutuando entre os ovos e o bacon do café da manhã e atrás da cara de Buddy Willard, o responsável por me fazer vê-la, e logo senti que estava levando a cabeça do cadáver por aí, presa por uma cordinha como um balão preto e sem nariz fedendo a vinagre" (PLATH, 2014, p. 8).

A última edição recria também a construção "preta" ao descrever a cabeça, sendo o termo omitido na de 1999, distanciando-se esta última ainda mais do período: " [...] and pretty soon I felt as thought I were carrying that cadaver's head around with me on a string, like some black, noseless balloon stinking of vinegar" (PLATH, 2005, p. 2).

A edição brasileira de 2014 parece preferir esse vocabulário mais simples, como vimos acima, mas, ao mesmo tempo, torna as cenas mais vívidas, emulando uma dinâmica do texto de partida, e conferindo maior plasticidade às imagens narradas, que, pela simplicidade das construções frásicas da tradução mais nova, pode tornar a ação do romance mais acessível imageticamente.

Mais à frente, encontramos outro momento em que a escolha de termos da tradução da editora Record, anterior à da Biblioteca Azul, segue uma tônica mais erudita, lançando mão de termo pouco usual no português e evidenciando um maior apuro no uso do vocabulário na tradução de 1999:

Haveria um buraco escuro de sete palmos cavado no chão duro. Aquela sombra se juntaria a essa, o sol amarelado selaria a ferida na brancura da neve, e uma nova nevasca apagaria os traços da cova de Joan.

Dei um longo suspiro e ouvi a velha bazófia do meu coração.

Eu sou eu sou eu sou. (PLATH, 1999, p. 266). 
O trecho, no texto de partida, diz:

There would be a black, six-foot-deep hacked in the hard ground. That shadow would marry this shadow, and the peculiar, yellowish soil of our locality seal the wound in the whiteness, and yet another snowfall erase the traces of newness in Joan's grave.

I took a deep breath and listened to the old brag of my heart. I am, I am, I am. (PLATH, 2005, p. 243).

A tradução brasileira mais antiga descreve "the old brag" como "a velha bazófia". Na edição de 2014, encontramos, simplesmente, "a batida presunçosa de meu coração" (2014, p. 273). A segunda continua a trazer termos simplificados, aproximando-se do original. " $\mathrm{Ba}$ zófia", pouco frequente na linguagem falada corrente, caracteriza a tradução de Horta como tendo um escopo literário mais tradicional.

Percebemos, finalmente, que a tradução mais recente decide não verter para o português certas referências, mantendo-as em inglês, ao contrário da edição de 1999. Versos, trechos de música, referências culturais americanas, na tradução de Mattoso, tendem a se manter no idioma de origem. Quando, num determinado momento da trama, uma canção popular surge, soando ao redor onde a personagem esquia, a tradução de 2014 traz:

Do sopé da pista de esqui, a imitação de chalé rústico assobiava canções populares silêncio adentro.

Gazing down on the Jungfrau

From our chalet for two... (PLATH, 2014, p. 107).

A tradução de 1999, por sua vez, traduz o trecho da canção:

Por cima do silêncio, vinha o som de canções populares que saíam da cabana de falsos troncos de árvores, no sopé da montanha. 
Vejo na montanha suiça

Nosso chalé para dois... (PLATH, 1999, p. 105).

O primeiro excerto, de 2014, parece marcar a identidade do texto traduzido, assinalando discretamente que não se trata de uma obra escrita em português e que deve ser entendida em seu contexto.

Mas, o que garantiria tal gesto tradutório à edição mais recente? Parece afinar-se à ideia de que a tradução de 2014 não apenas reapresenta Sylvia Plath ao público brasileiro, mas afirma sua escrita como a escrita do mito Sylvia Plath, que escreve em inglês, que é poeta americana, que se suicidou na década de 60 , que traz todo um passado consigo, com suas circunstâncias biográficas, sem abandonar a imagem da jovem loura poeta suicida na sociedade americana.

Dá-nos fé disso a capa da edição de 2014, com a foto do rosto da própria Sylvia, em cor-de-rosa, projetado sob padrões geométricos que se desenham em cima de sua face. É a figura da autoria no centro da publicação, com tudo o que o nome de Sylvia acumulou.

A Biblioteca Azul publicara também, pela mesma época, edição especial do livro, com os desenhos de Sylvia, bem como algumas cartas que a autora trocara com a mãe e com o então marido, Ted Hughes. Houve todo um incremento à imagem moderna da poeta, e sua intensificação, com o lançamento desses desenhos, até então inéditos no Brasil.

As cartas, que acompanharam a publicação de seus rascunhos e esboços, dão testemunho de uma história de amor e de vida conturbada, ajudando a compor o mosaico misterioso, mas já bastante devassado da vida íntima e privada da mulher Sylvia Plath. Os desenhos são da época de sua lua-de-mel, bem como as cartas, alocadas temporalmente entre pouco antes e pouco depois de seu casamento com o poeta Ted Hughes, em uma atmosfera de triste 
alegria, de luminosidade melancólica, antecipando os dramas domésticos que enfrentaria Sylvia mais tarde em sua vida.

Percebemos que o mercado editorial bebe da fonte de diversos mitos e as traduções compõem o coração desse mercado. Contudo, a escritura ficcional do livro em questão, ao fim e ao cabo, parece munido de intenções poéticas e artísticas, independente da dinâmica do mercado.

No final das contas, com a linguagem mais próxima ou mais distante da construção frasal inglesa, ambas as traduções, cada uma a seu modo, conseguem capturar o mais importante: o apuro plástico de Sylvia Plath neste romance. É o que se observa, como exemplo final, na seguinte cena:

[...]. Resolvi que ia passar o verão escrevendo um romance.

[...]. Coloquei a mesa de jogo no jardim de inverno que ficava entre a casa e a garagem.

Um pé de silindra formava uma grande muralha que escondia a rua; a casa e a garagem tapavam o outro lado; uma moita de bétulas e uma cerca viva me protegiam da Sra. Ockenden.

[...]. De uma perspectiva distante e diversa, me vi sentada no jardim de inverno, cercada por dois muros de madeira branca, um pé de silindra, uma moita de bétulas e uma cerca viva - eu, pequenina como uma boneca numa casa de brinquedo. (1999, p. 133).

Na edição de 2014:

[...]. Decidi que passaria o verão escrevendo um romance.

[...]. Instalei a mesa de carteado na passagem coberta entre a casa e a garagem.

Uma grande moita de jasmins bloqueava a visão da frente, 
as paredes da casa e da garagem tampavam os lados, e um grupo de bétulas e uma cerca viva me protegiam da Sra. Ockenden ao fundo.

[...]. De uma distância imaginária, vi a mim mesma sentada na passagem, rodeada por duas paredes de madeira branca, uma moita de jasmins, um grupo de bétulas e uma cerca viva, pequena como uma boneca numa casa de bonecas. (2014, p. 135).

Ambas mantêm viva a atmosfera da cena, que, no original, descreve: "[...] From another, distanced mind, I saw myself sitting on the breezeway, sorrounded by two white clapboard walls, a mock Orange bush and a clump of birches and a box hedge, small as a doll in a doll's house. " (2005, p. 120).

O que concluímos é que, ainda que se assumam dicções diferenciadas, as duas edições recriam a beleza simples da escrita de Sylvia Plath, escrita que se apresenta não como um signo cifrado, mas como um quadro que se abre delicadamente ao leitor.

Recebido em: 28/03/2017

Aceito em: 08/07/2017

Publicado em setembro de 2017 